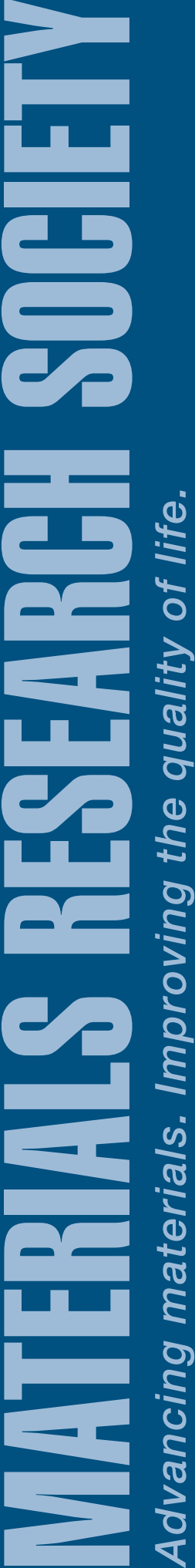

\author{
"If you want to make a change, be the best example of that change \\ and others will follow."
}

\title{
Diversity in MRS and in MRS leadership: Use your vote
}

The Materials Research Society strives to broaden participation and increase the effectiveness of everything we do, from committees to meetings to publications to outreach.

This letter is both a tutorial about, and a plea to consider, diversity in the upcoming election of MRS officers and board directors. If you are an MRS member, you will be receiving a ballot soon. For the future of the Society, it is important that you participate, and consider both the breadth and depth of the membership, and a diversity of leadership skills as you choose the Society's future leaders.

MRS is an outgrowth of dramatic changes in materials science that began in the $1960 \mathrm{~s}$. Before then, materials research was highly disciplinary (e.g., metallurgy or ceramics) and single-investigator centric.

MRS was formed on the basis of two revolutionary ideas. The first was that great innovations in materials and devices would ensue from an interdisciplinary approach to materials research. That is, by putting people with different technical backgrounds together, the diversity of approaches and ideas would lead to new materials, basic understanding, and new devices.

The second idea, consistent with the first, was that, because interdisciplinary research thrives on a diversity of approaches and ideas, MRS should promote leading-edge materials research wherever it occurs. Excellence in materials research is not limited to certain types of people, or people with a certain type of training, to specific types of institutions, or by the part of the globe in which the researcher is located. Thus, from its earliest days, MRS developed an explicit set of values for diversity in technical expertise, institution, gender, and geographical location that are applied to all volunteer positions. This practice has helped to maintain and promote MRS as a diverse, international organization.

As an MRS member, we need your help to ensure that this diversity is maintained in the selection of the officers and members of the Board of Directors, the Society's highest governing body. Soon you will receive information about the candidates and voting instructions via the Web. The MRS Nominating Committee has generated an outstanding list of candidates. We ask you to please keep MRS diversity in mind when selecting candidates.

In particular, while we have done very well in maintaining diversity in technical expertise, gender, and institution type on the board, we must work to maintain diversity in geographical representation. Unlike other societies that have a country or continent in their name, MRS was not created to represent a particular region of the world. It was created to promote excellence in materials research everywhere. Although its origins are in the United States, over $40 \%$ of the members are located outside the country. It is critical that the Board include 
leaders who can represent the membership, particularly in Europe and Asia, where the majority of non-U.S.-based MRS members live and work.

In addition, a new metric has become important for the Board of Directors in recent years: diversity in leadership experience. As the Society grows and takes on ever bigger and broader challenges, it is increasingly important to have a range of high-level leadership experiences and skills on the board. Having people who have held high-level leadership positions in business, government, other non-profits, and academe helps ensure that the board is able to interact with other large organizations effectively.

MRS has made a difference in the materials science world, and can continue to do so. We need you to participate! Please take the time to read the candidates' biographies and statements, select those that you think can best represent the Society, and vote.

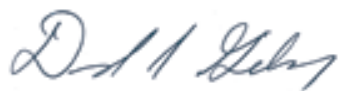

David S. Ginley

President

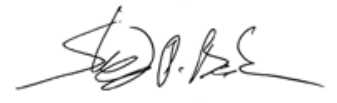

Shefford P. Baker

Immediate Past President

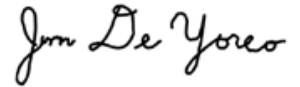

James J. De Yoreo

Vice President/President-Elect

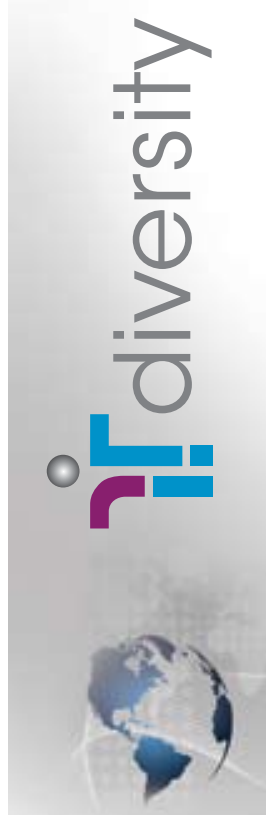

\section{MRS DIVERSITY STATEMENT}

The scientific and engineering communities must strive to become more inclusive, engaging all demographic groups in advancing science and technology. MRS recognizes that Diversity drives Innovation, Excellence, and New Discoveries. Although progress has been made, women and underrepresented groups still remain a largely untapped resource in research and innovation.

We affirm the critical role that professional societies must play at all levels of education and professional pursuits. Recent programs by many professional societies have provided benchmarking data collection, forums to discuss diversity issues in science and opportunities for professional development training. More needs to be done. The Materials Research Society therefore charges our membership and our leaders to continually engage the science and engineering enterprise, promoting greater participation from all demographic groups, proactively addressing barriers and fostering greater diversity wherever scientists and engineers are educated and employed.

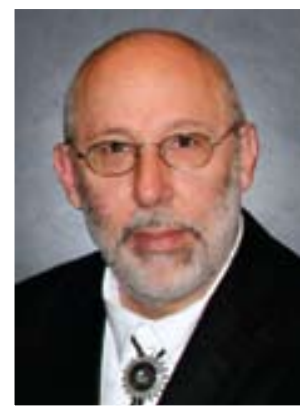

David S. Ginley President

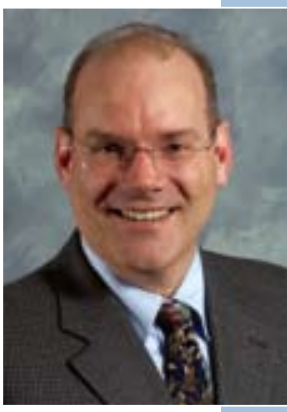

Shefford P. Baker Immediate Past President

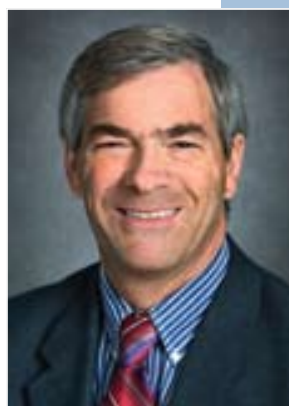

James J. De Yoreo Vice President/President-Elect

MRS has always been a member-driven Society. Voting is one of the most important ways that MRS members impact the future of the Society....and by extension materials research globally. So please vote! 